\title{
INQUÉRITO ENTRE MIGRANTES ATENDIDOS PELA CENTRAL DE TRIAGEM E ENCAMINHAMENTO, NA CAPITAL DO ESTADO DE SÃO PAULO, BRASIL. I. ASPECTOS DEMOGRÁFICOS *
}

Maria José Roncada **

\begin{abstract}
RSPU-B $/ 270$
RoNCADA, M. J. - Inquérito entre migrantes atendidos pela Central de Triagem e Encaminhamento, na capital do Estado de Säo Paulo, Brasil. I. Aspectos demográficos. Rev. Saúde públ., S. Paulo, 9:303-12, 1975.

Resumo: São descritos os aspectos demográficos de uma pesquisa sobre hiporitaminose $A$, realizada entre migrantes nacionais que passaram pela Central de Triagem e Encaminhamento (CETREN), na Capital do Estado de São Paulo, Brasil. Entre 1.097 individuos entrevistados, oriundos de todas as Regiōes do pais, de 15 a 60 anos de idade, cerca de dois terços eram do sexo masculino. A idade modal foi 22 anos. Foi apurada a procedência imediata $e$ remota, originando resultados que mostraram ser os Estados de Minas Gerais, Bahia e Pernambuco, zonas de repulsão de populações, atuando os Estados de Săo Paulo (Capital e interior) e Paraná como áreas de atração. Dentre os motivos apontados para o deslocamento atual, 45,3\% referiram-se a atividades primarias (trabalho em lavoura).
\end{abstract}

Unitermos: Migração interna. Migrantes, inquérito. Central de Triagem e Encaminhamento, São Paulo, Brasil.

Uma das constataçōes mais familiares aos estudiosos que se preocupam com as migraçôes. é a de que os movimentos populacionais tendem a operar através de determinados fluxos, originando assim as chamadas correntes migratórias ${ }^{5}$. Esses movimentos constituem respostas de determinados grupos sociais às diferenças regionais que acompanham as transformações econômicas por que passa uma determinada sociedade ${ }^{4}$.

Em nosso país, como se sabe, as principais áreas de repulsão encontram-se no Nordeste do país e delas partem correntes migratórias para outras regiōes, em busca de novas oportunidades. Entre as zonas de atração estão o Estado e a Capital de São Paulo.

Os migrantes nacionais que demandam à Capital de São Paulo buscam espontaneamente ou são encaminhados à Central de Triagem e Encaminhamento (CETREN), da Secretaria de Promoção Social do Estado de São Paulo, localizada no bairro do Cambuci.

A CETREN é uma instituição que funciona durante as 24 horas do dia, inclusive aos sábados e domingos. Inaugurada

* Trabalho baseado na tese de doutoramento apresentada à Faculdade de Saúde Pública da LSP, em 1973.

* Do Departamento de Nutrição da Faculdade de Saúde Pública da LisP - Avenida Dr. Arnaldo, 715 - São Paulo, SP - Brasil. 
RONCADA, M. J. - Inquérito entre migrantes atendidos pela Central de Triagem e Encaminhamento, na capital do Estado de São Paulo. I. Aspectos demográficos. Rev. Saúde públ., S. Paulo, 9:303-12, 1975.

a 26 de outubro de 1971 , recebeu 112.293 pessoas em seu primeiro ano de funcionamento. Desse total, 82.470 indivíduos (cerca de $75 \%$ ) tinham idade acima de 15 anos.

As pessoas que procuram a CETREN provêm de qualquer região do país (e mesmo do exterior), e tềm diferentes razões para aí se dirigirem: umas precisam de assistência médica, outras são encaminhadas pelo Serviço Social do Estado, outras necessitam documentos, mas a grande maioria procura trabalho e solicita a obtenção de passes gratuitos para conduzi-las ao interior do Estado ou para outros Estados da Federação, constituindo-se, portanto, essa maioria, por migrantes.

Durante o período de 18 de julho a 17 de agosto de 1972. fizemos um levantamento na CETREN, com a finalidade de estudar hiporitaminose $A$ em migrantes nacionais que por lá passaram. Essa investigação incluiu coleta de dados de identificação. dados demográficos e de hábitos alimentares, e ainda coleta de sangue para a dosagem de caroteno e vitamina $\mathrm{A}$.

Fomos incentivados a publicar os aspectos demográficos do nosso inquérito, embora assunto alheio à nossa especialidade, por ser bastante conhecida a dificuldade de obtenção de dados sobre migração, através de informação direta dos indivíduos envolvidos. A par do interesse diretamente ligado a nosso campo, as informações levantadas sobre idade, sexo, procedência. destino e motivos apresentados pelos migrantes para se deslocarem de um lugar a outro. representam informações relevantes em si, em termos de constatação de certas tendências que ocorrem, podendo fornecer subsîdios para outros estudos sobre o tema. Os aspectos bioquímicos e alimentares serão objeto de dois outros artigos.

\section{ME TODOLOGIA}

Estudamos 1.097 migrantes, de 15 a 60 anos de idade, dos dois sexos, que pas- saram algumas horas na CETREN, no período já mencionado.

Fizemos várias visitas prévias à CETREN. com o fito de tomarmos conhecimento preciso da rotina de trabalho da instituição, bem como realizar levantamento de dados estatísticos referentes ao seu funcionamento. Verificamos certa regularidade semanal na entrada dos migrantes. Assim, o grande contingente nordestino e da região Sudeste (excetuando-se o Estado de São Paulo) chegava, na maioria das vezes, às segundas, quartas e sextas-feiras à noite, no chamado "trem baiano"; os migrantes oriundos de outras regióes. e do próprio Estado, chegaram indistintamente a qualquer hora $\mathrm{e}$ em qualquer dia da semana.

O tempo máximo de permanência na CETREN é de 72 horas, mas a grande maioria deixava a entidade antes desse prazo.

Através do cadastro da CETREN pudemos selecionar os migrantes fichados a cada dia. Esta seleção consistia em desprezar indigentes e indivíduos sem documentos para ali encaminhados pela autoridade policial e que não apresentassem as características de verdadeiro migrante. Os 68 indivíduos que procederam da $\mathrm{Ca}-$ pital (Tabela 2) eram migrantes que estavam estabelecidos aqui há algum tempo e pretendiam se deslocar novamente.

Faziam parte da amostra diária os indivíduos que chegavam na véspera, a partir das 16 horas, até às 9 horas da manhã seguinte. Cremos ter conseguido boa representatividade na amostra. quer quanto à idade, sexo ou Regiões de procedência dos migrantes, quando comparados com os registros da CETREN.

No preenchimento de nossos formulários usávamos os dados das fichas cadastrais da CETREN referentes apenas ao número de matrícula (que era o mesmo para toda a família), ao nome, sexo e ida- 
RONCADA, M. J. - Inquérito entre migrantes atendidos pela Central de Triagem e Encaminhamento, na capital do Estado de São Paulo. I. Aspectos demográficos. Rev. Saúde públ., S. Paulo, 9:303-12, 1975.

de (mas esta era depois novamente inquirida pessoalmente, pois constatamos haver falhas com relação a esse item).

Nosso questionário permitiu-nos conhecer dados pessoais e demográficos, bem como outros relacionados com a saúde e o consumo dos principais alimentos ricos em caroteno e vitamina A. Relacionaremos a seguir apenas a parte do formulário referente a este trabalho:

1. Nome $\ldots \ldots \ldots \ldots \ldots \ldots \ldots \ldots$ Idade $: \ldots \ldots$ N. de Matrícula .....

2. Sexo: ............ Gestante: ............ Meses: ........

3. Nasceu em .................... Fstado $\ldots \ldots \ldots \ldots \ldots$

4. Veio de $\ldots \ldots \ldots \ldots \ldots \ldots$. Estado $: \ldots \ldots \ldots \ldots$ Chegou há.$\ldots \ldots \ldots$

5. Antes de viajar $\mathrm{p} /$ cá, morou em ......... Est.: ...... Tempo : ....

6. E antes disso, morou em ........... Est.: ...... Tempo : ....

7. Está indo para $\ldots \ldots \ldots \ldots \ldots \ldots \ldots \ldots \ldots \ldots$ Estado $\ldots \ldots \ldots \ldots \ldots$

8. Por que?

0 formulário, preenchido sempre pelo entrevistador, foi pré-testado 4 vezes entre os migrantes da CETREN, e as entrevistas foram sempre individuais, mesmo ao se tratar, por exemplo, dos dois membros de um casal. Isto permitiu-nos verificar a exatidão das informações prestadas por eles.

Quando fizemos o levantamento prévio da instituição, tivemos oportınidade de observar que a procedência dos migrantes era anotada nas fichas cadastrais. $\mathrm{Na}$ fase dos pré-testes verificamos porém que essa informação nem sempre era correta, devido em grande parte ao nível de instrução dos clientes da CETREN que, de modo geral, é bastante baixo, dificultando o trabalho dos escriturários encarregados do preenchimento das papeletas. Em virtude desse fato, introduzimos as perguntas de números 5 e 6 , em auxílio da de número 4 , já que muitas vezes os indivíduos informavam provir de determinada cidade que apenas lhes servira de parada provisória, para repouso ou troca da via de condução.
Durante o pré-teste contornamos também a dificuldade em localizar dentro da instituição o indivíduo amostrado, pois este somente se identificava ao nosso chamado quando proferíamos seu número de matrícula além do nome completo.

\section{RESULTADOS E COMENTARIOS}

Como já mencionamos, nossa amostra permitiu o levantamento de informações a respeito de 1.097 migrantes. No que se refere aos aspectos demográficos, pode-se constatar certas características de interesse; em primeiro lugar, verificou-se uma grande predominância de elementos do sexo masculino: aproximadamente $70 \%$ do total.

Quanto à idade (Tabela 1 e Figura 1), a predominância indiscutível para ambos os sexos está situada no grupo etário de 20 a 24 anos, seguida dos grupos de 25 a 29 anos e de 15 a 19 anos, com idade modal de 22 anos. Essas duas constatações reiteram o que tem sido freqüentemente observado nos estudos de migra- 
RONCADA, M. J. - Inquérito entre migrantes atendidos pela Central de Triagem e Encaminhamento, na capital do Estado de São Paulo. I. Aspectos demográficos. Rev. Saude públ., S. Paulo, 9:303-12, 1975.

T A B E L A 1

Composição da amostra segundo sexo e grupos etários de migrantes, CETREN, São Paulo, 1972

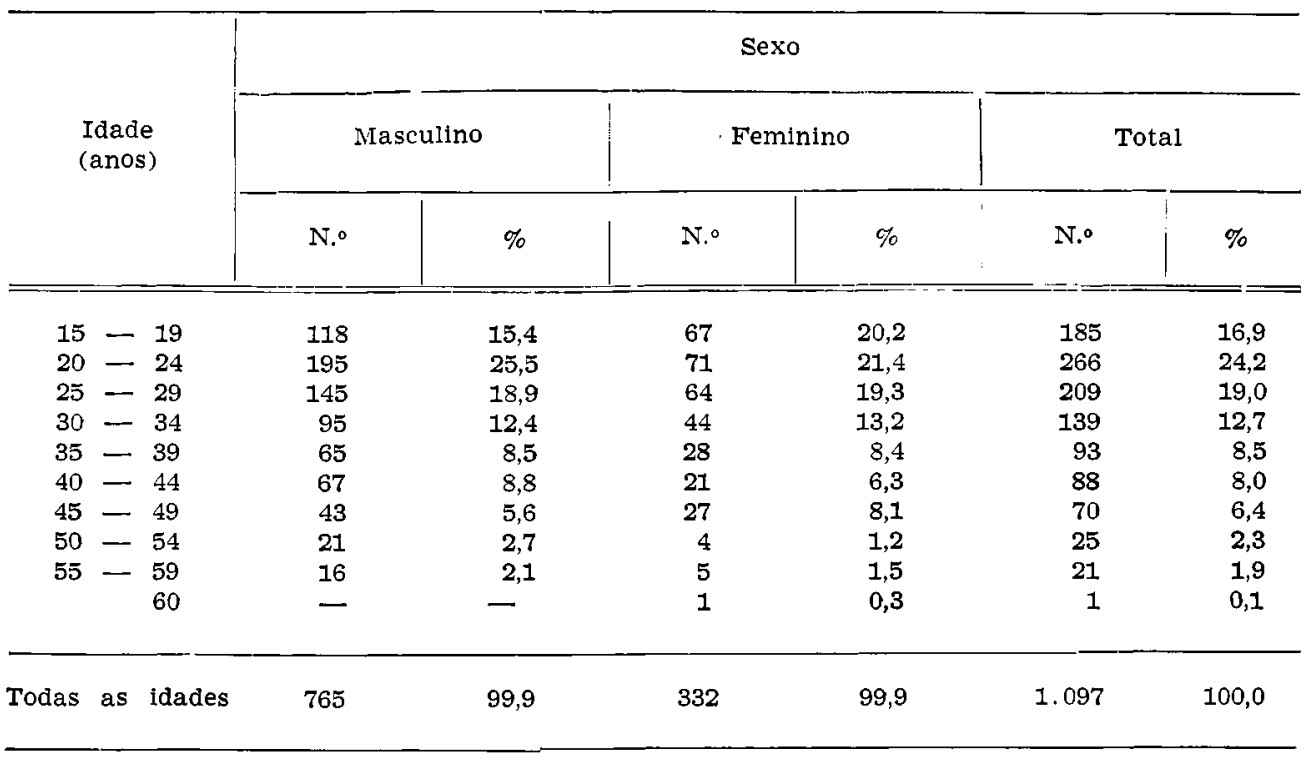

ção, ou seja, a tendência à predominância de migração de indivíduos do sexo masculino e de idades jovens, em torno do início da idade economicamente ativa ${ }^{2}$.

E interessante mencionar que havia um grande número de indivíduos do sexo masculino, com idade entre 18 e 25 anos,

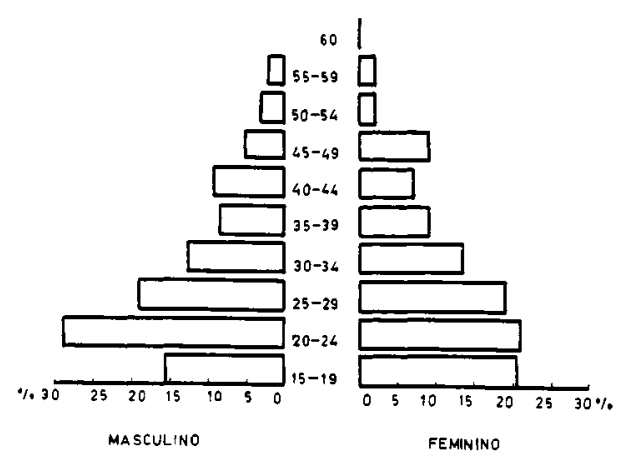

Fig. 1 - Composição da amostra (1.097 individuos) por sexo e idade. CETREN, são Paulo, 1972. solteiros, que vinham sós para São Paulo, com o propósito de conseguirem empregos em atividades secundárias ou terciárias. Os migrantes que se dirigiam de uma para outra região agrícola (atividades primárias para atividades primárias) eram, em geral, casados e acompanhados pelas famílias.

Através da Tabela 2 podemos observar os deslocamentos do trabalhador naciona] que passou pela CETREN, e mesmo a direção dos fluxos migratórios. Nossos migrantes apresentaram grande mobilidade geográfica, pois procediam geralmente de locais outros que não sua terra natal. Existe como que uma redistribuição dos recursos humanos, como decorrência das modificações nas oportunidades oferecidas pelas diferentes regiões do país. Mas a migração de uma para outra zona rural apresenta sempre uma movimentação mais intensa do que a migração rural-urbana ?. Analisando os dados referentes aos Estados 
RONCADA, M. J. - Inquérito entre migrantes atendidos pela Central de Triagem e Encaminhamento, na capital do Estado de São Paulo. I. Aspectos demográficos. Rev. Saúdo puibl., S. Paulo, 9:303-12, 1975.

TABEIA 2

Naturalidade, procedência e destino dos migrantes, CETREN, São Paulo, 1972

\begin{tabular}{|c|c|c|c|c|c|c|}
\hline \multirow{2}{*}{ Estados } & \multicolumn{2}{|c|}{ Naturalidade } & \multicolumn{2}{|c|}{ Procedência } & \multicolumn{2}{|c|}{ Destino } \\
\hline & N. 0 & $\%$ & $\mathrm{~N} .{ }^{\circ}$ & $\%$ & N.o & $\%$ \\
\hline $\mathrm{SP}_{\mathrm{c}} *$ & 10 & 0,9 & 68 & 6,2 & 116 & 10,6 \\
\hline $\mathrm{SP}_{\mathbf{i}} * *$ & 122 & 11,1 & 237 & 21,6 & 379 & 34,5 \\
\hline $\mathrm{AM}$ & 1 & 0,1 & 2 & 0,2 & 4 & 0,4 \\
\hline PA & 2 & 0,2 & 1 & 0,1 & - & - \\
\hline MA & I & 0,1 & 一 & - & - & - \\
\hline PI & 2 & 0,2 & 3 & 0,3 & 1 & 0,1 \\
\hline $\mathrm{CE}$ & 35 & 3,2 & 19 & 1,7 & 2 & 0,2 \\
\hline RN & 6 & 0,5 & 1 & 0,1 & $\rightarrow$ & - \\
\hline $\mathrm{PB}$ & 25 & 2,3 & 4 & 0,4 & 5 & 0,4 \\
\hline$P E$ & 110 & 10,0 & 60 & 5,5 & 30 & 2,7 \\
\hline $\mathrm{AL}$ & 60 & 5,5 & 33 & 3,0 & 7 & 0,6 \\
\hline $\mathrm{SE}$ & 14 & 1,3 & 7 & 0,6 & 6 & 0,5 \\
\hline $\mathrm{BA}$ & 21.4 & 19,5 & 131 & 11,9 & 49 & 4,5 \\
\hline MG & 413 & 37,6 & 333 & 30,3 & 81 & 7,4 \\
\hline ES & 16 & 1,5 & 3 & 0,3 & 1 & 0,1 \\
\hline RJ & 9 & 0,8 & 11 & 1,0 & 14 & 1,3 \\
\hline GB & 8 & 0,7 & 25 & 2,3 & 27 & 2,5 \\
\hline $\mathrm{PR}$ & 24 & 2,2 & 74 & 6,7 & 290 & 26,4 \\
\hline sc & 5 & 0,4 & 2 & 0,2 & 5 & 0,4 \\
\hline $\mathrm{RS}$ & 11 & 1,0 & 3 & 0,3 & 2 & 0,2 \\
\hline MT & 5 & 0,4 & 26 & 2,4 & 34 & 3,1 \\
\hline GO & 1 & 0,1 & 41 & 3,7 & 19 & 1,7 \\
\hline DF & - & - & 6 & 0,5 & 4 & 0,4 \\
\hline Exterior e Ignor. & 3 & 0,3 & 7 & 0,6 & 21 & 1,9 \\
\hline Total & 1.097 & 99,9 & 1.097 & 99,9 & 1.097 & 99,9 \\
\hline
\end{tabular}

* Estado de São Paulo - Capital

* Estado de São Paulo - Interior

do Nordeste e de Minas Gerais, verificamos que apenas uma parcela dos inquiridos provinha diretamente de seu Estado natal; os demais, portanto, já haviam emigrado anteriormente, comprovando também uma tendência à migração por etapas, mencionada como uma possível característica das migrações internas ${ }^{5}$. Podemos dizer que estes Estados funcionam como zonas de emissão ou repulsão, pois neles o número de emigrantes supera de muito o de imigrantes. Para os Estados do Amazonas, Rio de Janeiro, Guanabara, Paraná, Mato Grosso, Goiás e São Paulo
(Capital e interior) observa-se o inverso, ou seja, são zonas de atração e, portanto, o número de imigrantes é superior ao de emigrantes (Figura 2).

A Figura 2 é bem elucidativa, pois permite uma visualização do agrupamento dos Estados nos dois tipos mencionados, configurando-se, por assim dizer, uma contrapartida dos Estados de atração com relação aos Estados de repulsão.

Quanto ao Estado de Goiás, apesar de ser uma zona de atração, predominou o número dos que de lá procediam sobre o dos que para lá se dirigiam, devido ao 
RONCADA, M. J. - Inquérito entre migrantes atendidos pela Central de Triagem e Encaminhamento, na capital do Estado de São Paulo. I. Aspectos demográficos. Rev. Saúde públ., S. Paulo, 9:303-12, 1975.

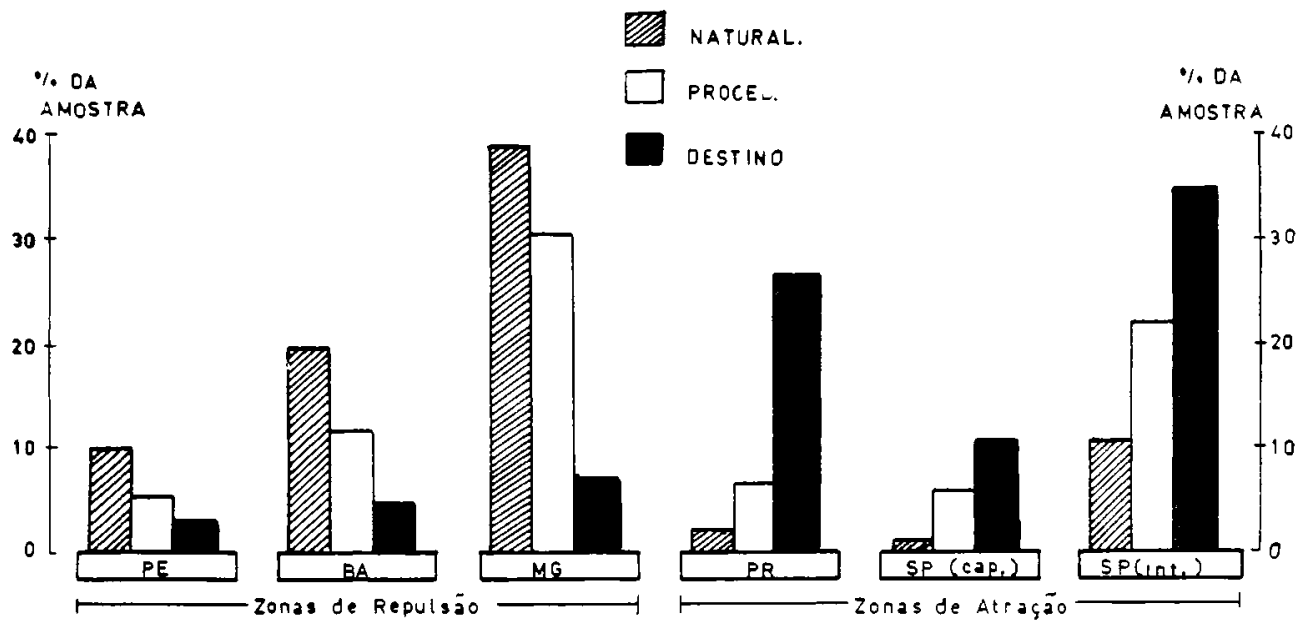

Fig. 2 - Distribuição percentual de migrantes, segundo naturalidade, procedência, destino, em alguns Estados que atuam como zonas de repulsão e outros como zonas de atração. CETREN, Sāo Paulo, 1972.

término da colheita de cereais naquela parte do ano.

Através da pergunta número 8 do formulário, apuramos os motivos do deslocamento atual dessa população. Classificando as respostas, conseguimos agrupar os motivos apontados em sete categorias: trabalho na lavoura, exercício de atividades diferentes (secundárias ou terciárias), acompanhamento à família, tratamento de saúde, regresso ao lar, passeio e ignorado. Geralmente quem apresentava como motivo de seu deslocamento o acompanhamento à família, eram algumas esposas e filhos com menos de 18 anos, além de senhoras mais idosas, parentes próximas de um ou outro casal de migrantes. Quem alegava ter vindo a São Paulo para tratamento de saúde, vinha com intenção de ser atendido no Hospital das Clínicas da Universidade de São Paulo. Quando o motivo apontado foi "passeio" o indivíduo recorria à CETREN com o fito de obter passe gratuito para visitar os familiares que não haviam emigrado. Os que ignoravam os motivos de seu deslocamento, ou eram indivíduos que migra- ram apenas contagiados pelo entusiasmo de algum parente ou amigo a quem acompanhavam, não se preocupando de antemão $\mathrm{com}$ a atividade na qual se fixariam, ou eram pessoas sem condiçóes de tomar decisões as mais simples. Por isso, não podemos generalizar opinióes como a de técnicos da $\mathrm{OMS}^{6}$ ou de autores nacionais ${ }^{1}$, segundo as quais, via de regra, os indivíduos que se deslocam são mais aptos e vigorosos do que os que ficam.

A Tabela 3 aponta os motivos apresentados pelos migrantes para seu atual deslocamento, segundo os Estados de procedência. Verificamos por ela que os três Estados dos quais procederam os migrantes em maior número foram, respectivamente. Minas Gerais, São Paulo (interior) e Bahia. Não chegou a atingir 50\% o número dos migrantes que declararam pretender trabalhar na lavoura $(45,3 \%)$. Contudo, esse dado mostra também as expectativas dos indivíduos quanto à sua atividade futura. É comum supor-se que os movimentos migratórios que acompanham o processo de desenvolvimento sejam predominantemente do tipo rural-ur- 
RONCADA, M. J. - Inquérito entre migrantes atendidos pela Central de Triagem e Encaminhamento, na capital do Estado de São Paulo. I. Aspectos demográficos, Rev. Saúde públ., S. Paulo, 9:303-12, 1975.

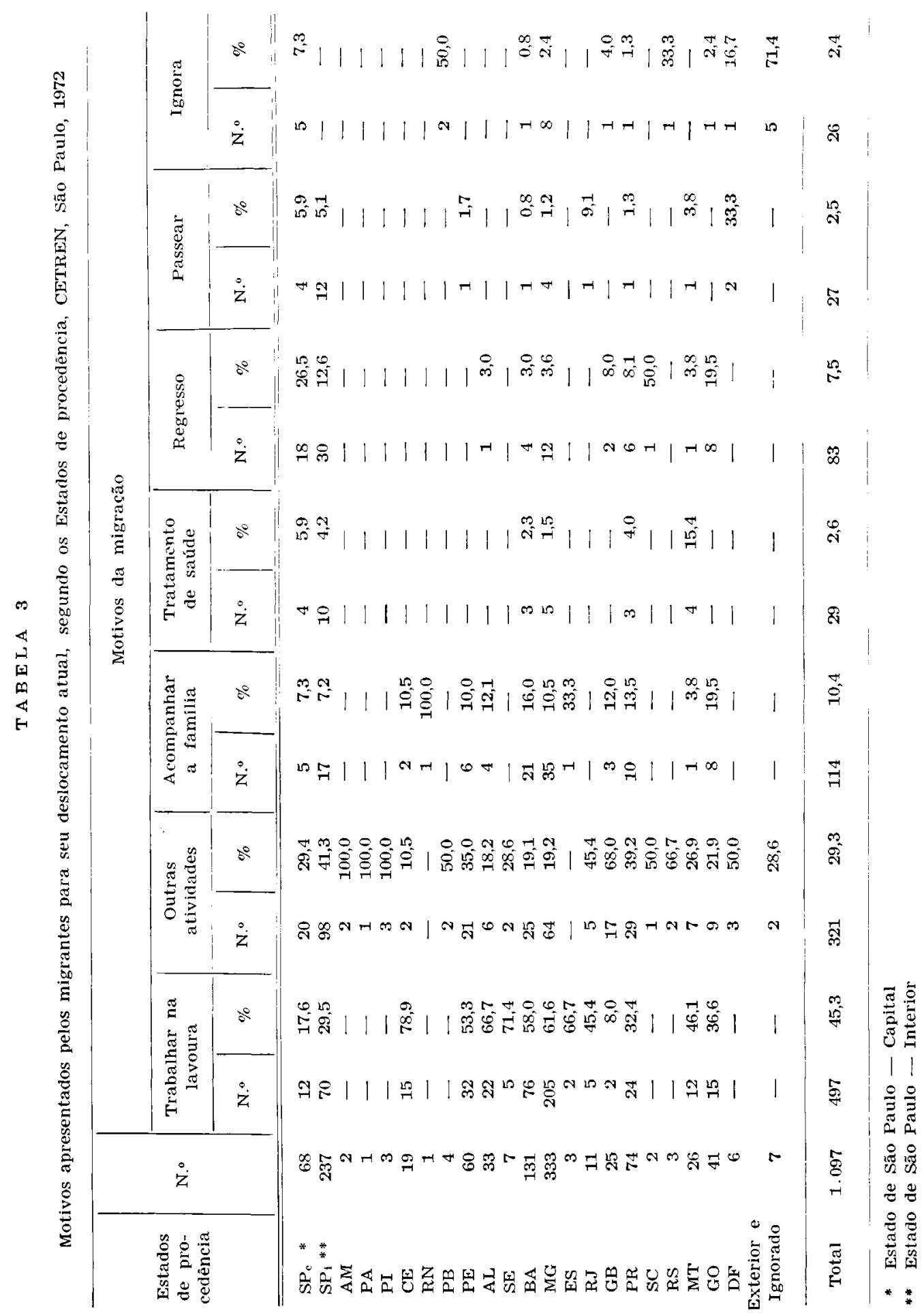


RONCADA, M. J. - Inquérito entre migrantes atendidos pela Central de Triagem e Encaminhamento, na capital do Estado de São Paulo. I. Aspectos demográficos. Rev. Saude públ., S. Paulo, 9:303-12, 1975.

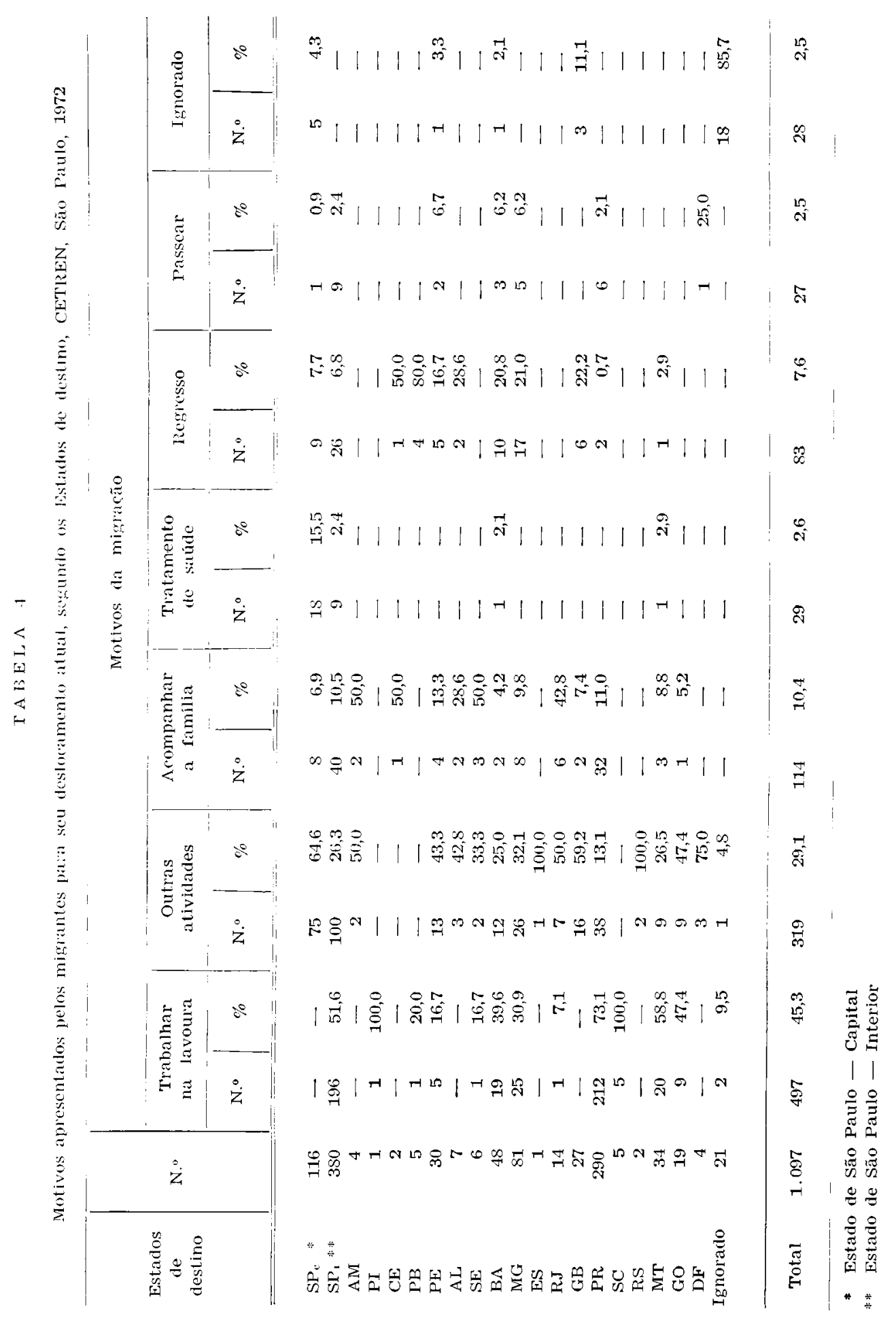


RONCADA, II. J. - Inquérito entre migrantes atendidos pela Central de Triagem e Encaminhamento, na capital do Estado de São Paulo. I. Aspectos demográficos. Rev. Saúde públ., S. Paulo, 9:303-12, 1975.

bano. com deslocamentos de trabalhadores agrícolas para atividades citadinas. Verifica-se aqui que, talvez, de maneira mais realista, uma parcela considerável desse contingente populacional intencionalmente se dirige a outra atividade primária.

Quando se observa os dados da Tabela 4, que classifica os motivos da migração segundo os Estados de destino, essa intenção ganha mais realismo ao se verificar que é bem considerárel o número de migrantes que pretendia se encaminhar para a lavoura no Estado do Paraná e interior do Estado de São Paulo. Os indivíduos que se destinaram à Capital de São Paulo e à cidade e ao Estado do Rio de Janeiro declararam, geralmente, estarem em busca de emprego em construção civil.

Segundo Figueiredo e col. ${ }^{3}$, mais de $60 \%$ da totalidade de migrantes mineiros encontram-se em São Paulo, trabalhando na construção civil, indústria e comércio varejista. Surgem logo após os baianos e pernambucanos, atuando mais efetivamente no setor secundário, na construção civil, e no setor terciário, em comércio varejista.

Os chefes dos dois casais que se destinaram ao Amazonas informaram pretender trabalhar na Rodovia Transamazônica.

Concluindo. os dados aqui apresentados confirmam algumas tendências já encontradas em outros estudos, divergem de outras constatações e especificam algumas caracteristicas por trazerem informaçôes diretas sobre um determinado tipo de migrante (que passa pela CETREN), sobre o qual pouco se conhece.

\section{AGRADECIMIN TOS}

À Dra. Neide Lopes Patarra, do Centro de Estudos de Dinâmica Populacional (CEDIP), da Universidade de São Paulo, pelas valiosas sugestóes e revisão.

RSPU-B $/ 270$

RoNCADA. M. T. - [Sumey conducted among migrants going through the "Central de Triagem e Encaminhamento (CETREN)" in S. Paulo City, Brazil. I. Demographic aspects]. Rev. Saúde públ., S. Paulo, 9:303-12, 1975.

SUMmary: In the mresent study the demographic aspects of migrants are described. The data were collected at the same time as blood was collected for a study on vitamin $A$ among the same subjects. A sample of migrants passing through the CETREN in S. Paulo, SP, Brazil, was taken, comprising 1.097 subjects. The subjects came from all regions of Brazil, buing 15 to 60 years of age. Roughly two thirds were males. Modal age was 22 years. Both remote and immediate origin were investigated and it was found that the States of Minas Gerais, Bahia and Pernambuco were repulsion areas and that, on the other hand, the States of $\mathrm{S}$. Paulo (both Capital and hinterland) and Parana were attraction areas. Among the motives for migration mentioned by the subjects $45.9 \%$ refered to primary activities (agricultural labor).

UNITERMS: Migration domestic. Transients and migrants. S. Paulo, Brazil. 
RONCADA, M. J. - Inquérito entre migrantes atendidos pela Central de Triagem e Encaminhamento, na capital do Estado de São Paulo, I. Aspectos demográficos. Rev. Sáude pübl., S. Paulo, 9:303-12, 1975 .

\section{REFERENCIAS BIBLIOGRAFICAS}

1. ALMEIDA, V. U. \& MENDES SOBRINHO O. T. - Migração rural-urbana: aspectos da convergência de população do interior e outras localidades para a Capital do Estado de Sáo Paulo. São Paulo, Secretaria da Agricultura, Diretoria de Publicidade Agricola, 1951.

2. BOSCO, S. H. \& JORDAO NETTO, A. Migraçóes. São Paulo, Secretaria da Agricultura, Departamento de Imigração e Colonizaçāo, 1967.

3. FIGUEIREDO, J. P. de et al, - Correntes migratórias. Finans. públ, $\mathbf{3 2}$ : 19-36, 1972.

4. GERMANI, G. - Asimilación de inmigrantes en el medio urbano: notas metodológicas. Rev. latinoamer. Sociol. 1:158-77, 1965
5. LEE, E. S. - A theory of migration. Demography, 3:47-57, 1966.

6. ORGANIZACIÓN MUNDIAL DE LA SALUD. Comité de Expertos en Estadistica Sanitaria. Ginebra, 1966. Los métodos epidemiológicos en el estudio de las enfermedades cronicas: $11 .^{\circ}$ informe. Ginebra, 1967. (Ser. Inf. técn., 365).

7. PASTORE, J. - Migração, mobilidade social e desenvolvimento econômico. Cienc. econom. soc., Osasco, 6:56-78, 1971.

Recebido para publicação em 05-06-75

Aprovado para publicacão em 30-06-75 